\title{
Discussion on Several Safety and Stability Problems of Large Receiving-End Power Grid after AC UHV Access
}

\author{
Guangyao Yu, Tianhao Wang, Guodong Li, Jian Zhang and Zhiqiang Chong \\ State Grid Tianjin Electric Power Research Institute, Tianjin 300384,China
}

\begin{abstract}
With the UHV power grid into a period of rapid development, bi-coupled electromagnetic loop network or even $1000 \mathrm{kV} / 500 \mathrm{kV} / 220 \mathrm{kV}$ tri-coupled electromagnetic loop network will be widely formed by the receiving end after UHV project landing. Changes in the structure and operation characteristics of grid bring challenges to the security and stability operation of power grid. This paper discusses 3 problems which could cause operation faults in aspects of short circuit current, reactive power and voltage stability and power transfer in network respectively, and gives relevant measures and guidance suggestions to adjust risks which UHV brought in Tianjin.
\end{abstract}

Keywords-short-circuit current; reactive power; power transfer

\section{INTRODUCTION}

When state decide to guide "4-AC-UHV (1000kV) \&4-DC-UHV $(800 \mathrm{kV})$ transmission project" as a symbol into the Air Pollution Control Action Plan (APCAP), the UHV power grid steps into a new stage of rapid development, as the same time, more and more UHV projects landing will bring grid operation property changes for each provincial company such as the Beijing-Tianjin-Hebei in North China, Jiangsu-Zhejiang-Shanghai in East China, Hunan-Hubei in central China, UHV access to these large-scale power grid by the end puts forward new opportunities and challenges.

Taking analysis from power grid structure level, $1000 \mathrm{kV} / 500 \mathrm{kV}$ bi-coupled electromagnetic loop network or even $1000 \mathrm{kV} / 500 \mathrm{kV} / 220 \mathrm{kV}$ tri-coupled electromagnetic loop network will be widely formed by the receiving end in the early stages of the development of UHV power grid, In spite of the electromagnetic loop network have beneficial effect on taking full advantage of equipment transmission capacity ,ensuring reliable power supply, improving network power distribution reliability and other aspects[1], there are some drawbacks and security risks that can not be ignored in the operation of electromagnetic loop networks, including transient or dynamic stability problems, short-circuit current problems, thermal stability problems, etc[1]. for UHV grid and large-scale receiving network, most of all, serious safety hazards in power grid stable operation. In this paper, three operation perils of short-circuit current, thermal stability and reactive power- voltage stabilization which is confronted after UHV grid landing have been considered, Discussion in-depth will be conducted according to the operation adaptability research work of UHV grid access to Tianjin.

\section{ShORT-CIRCUIT CURRENT PROBlEMS}

Short circuit current analysis is one of the most important contents of power system security and stability analysis. The UHV transmission system is connected to the receiving end of the $500 \mathrm{kV}$ grid through the $500 \mathrm{kV}$ UHV substation, on account of the grid structure changes and $500 \mathrm{kV}$ power supply injection, short-circuit current often exceeds standard level by the receiving end. At present, exceeding short-circuit current stations mainly concentrated in UHV near zone, even worse some plants encountered serious short-circuit current cases. In addition, large-scale city receiving end with close packed grid structure power grid is more prone to go beyond short-circuit current limits exceeded the situation, Tianjin power grid is one of the most typical sample is in North China area. After the operation of UHV AC transmission project of Ximeng-Shandong and West mengxi- South Tianjin, the $500 \mathrm{kV}$ UHV South Tianjin Station bus and the nearby Wuzhuang and Jinghai station all suffered serious short-circuit current exceeding limits. Applying the transient stability analysis module to calculate the short-circuit current (three-phase short circuit) of Tianjin power grid after UHV access based on the power system simulation analysis tool PSD-BPA which shows that the short-circuit current level of Wuzhuang, Jinghai and South Tianjin station $500 \mathrm{kV}$ bus exceeded the switch breaking capacity (63kA), Wuzhuang, Jinghai station $500 \mathrm{kV}$ bus short-circuit current even reached $70 \mathrm{kA}$ in this case, as shown in Table I.

Currently, the general switch breaking capacity of circuit breaker in $500 \mathrm{kV}$ station is $63 \mathrm{kA}$, it is possible to change circuit breaker, if UHV near district station existed $50 \mathrm{kA}$ circuit breaker, such as Tianjin power grid adopted 2 circuit breaker Switch replacements in Wu Zhuang, Bin Hai station. Other short circuit current control measures including bus split running, circuit disconnection, line-reactor, fault current limiter (FCL), high impedance transformer installation, etc[2-3-5].Current limit devices are not widely used at this period over the state, there is a typical application in $500 \mathrm{kV}$ North Shanghai power grid which installed series $28 \Omega$ resistance but not in other provincial power grid company. Adjusting gird structure and operation mode are generally used current limit measures to handle short circuit current out-of-limit, namely the methods mentioned above.

East China power grid, for example, according to the UHV planning and construction situation, took short circuit current 
control measure with "series running + circuit disconnection "[2]. Tianjin $500 \mathrm{kV}$ network power grid frame size is not quite big, and its wiring connection in substation adopted incomplete $3 / 2$ pattern wiring connection, dissatisfied control short-circuit current operation conditions to use "out of string". There are two main options to choose from calculation and analysis results. In scheme 1 , the current limiting reactance could be installed on the line. After $15 \Omega$ series resistance had been placed on the four lines for Jinghai- South Tianjin double-circuit line and Wuzhuang-Jinghai double-circuit line, the short-circuit current level of Wuzhuang $500 \mathrm{kV}$ bus line had dropped to $67.45 \mathrm{kA}$, but still exceeded $500 \mathrm{kV}$ circuit breaker switch capacity, all short-circuit current control results were showed in Table I, another $500 \mathrm{kV}$ line disconnection should be practiced in order to achieve control requirements after verification. The second scheme is to adjust the grid structure to limit the short-circuit current. When the Wuzhuang-Banqiao single-circuit line is disconnected meanwhile splitting the UHV $500 \mathrm{kV}$ South Tianjin Station bus line, the short-circuit current of the $500 \mathrm{kV}$ Tianjin Power Grid had obviously fallen down below the interrupting capacity, all short-circuit current control results were showed in Table I, The feasible control choice is scheme 2 after a comprehensive analysis.

TABLE I. COMPARATIVE EFFECTS OF DIFFERENT CONTROL SCHEMES

\begin{tabular}{|c|c|c|c|}
\hline $\begin{array}{l}\text { Short } \\
\text { circuit } \\
\text { current(kA) }\end{array}$ \\
\hline Schemes
\end{tabular}

Furthermore, the control short-circuit current measure of adjusting grid structure, on one could reduce the short-circuit current level, one the other hand could impair the power structure strength or weaken the power supply security. With the progress of technology, equipment with current limiting devices of short circuit current control measures will be gradually popularized and applied.

\section{Reactive Power Voltage Stability Problems}

The voltage of UHV grid and its nearby $500 \mathrm{kV}$ power is within the reasonable range, which is the main research content of the receiving end adaption after the of UHV grid access.

Under the same conditions, the UHV line charging power is 4 times that of $500 \mathrm{kV}$ line charging power. In the light-load power flow or part of the fault mode, it is expected that the UHV power grid will deliver more reactive power to the 500 $\mathrm{kV}$ power grid, significantly elevating the $500 \mathrm{kV}$ substation voltage level near the UHV landing districts, on the contrary, reducing $500 \mathrm{kV}$ substation near area operation voltage [4].Based on the study of the Changzhi-Nanyang-Jingmen UHV AC demonstration project, a more complete conclusion is drawn that the voltage fluctuation of UHV near-region power station depends on the interconnection line transmission power, the amplitude of power fluctuation, line impedance value, three-phase short-circuit capacity of bus[6].

Therefore, strict verification should be taken before UHV landing, like reactive balance between UHV and $500 \mathrm{kV}$ power grid, voltage coordination and control features. Taking the UHV power plants and substations near area into consideration if necessary and it is appropriate to carry out reactive voltage optimization, to adjust placement timely within the area of reactive power configuration so that to cope with power flow changes in UHV.

In addition, it should be noted that, the receiving grid external power proportion will gradually increase with the UHV landing, units operation in relevant area will be restricted, and thus power grid supply capacity will also decline accordingly. Therefore, it is necessary to carry out research on grid voltage stability under the condition of large proportion of receiving grid external power, to determine the grid voltage weak area and take essential measures to ensure power system reactive voltage within a reasonable range.

\section{POWER TRANSFER PROBLEMS}

Under the normal operation mode, the measures can be taken to protect the UHV grid and the receiving area equipment near the landing area in the safe operation range. The $500 \mathrm{kV}$ power grid generally adopted transmission line with $4 \times$ $400 \mathrm{~mm}$ diameter which transmission capacity is $1000 \mathrm{MW}$, meanwhile line with $8 \times 630 \mathrm{~mm}$ diameter was applied in $1000 \mathrm{kV}$ power grid level which can convey feeding power above $4000 \mathrm{MW}$, so there is a huge transmission capacity gap between two kind of lines. Therefore, when the $1000 \mathrm{kV}$ circuits in line I or II suddenly quit the operation, it is easy to cause a large number of power flow transfer from $1000 \mathrm{kV}$ to $500 \mathrm{kV} / 220 \mathrm{kV}$ power grid. An overload risk is expected to occur in transmission channel, especially in part of channel which circuit network has not been formed. Taking Tianjin as an example, the power system analysis software tool PSD-BPA was used to simulate the situation of "Mengxi- South Tianjin " and "Ximeng-Shandong" UHV project. When the N-1 fault occurred on UHV grid lines, it is showed that about $30 \%$ power flow was transferred in $500 \mathrm{kV}$ and $220 \mathrm{kV}$ power grid in total $70 \%$. ratio of power-transferring. There is certain transmission power $2720 \mathrm{MW}$ which UHV grid could reach in major fault case, afterwards a huge surge appears in power transfer channel particularly in Tianjin area $500 \mathrm{kV}$ "Lutai-Binhai-Banqiao-South Tianjin" channel. As the single-circuit transmission bridge between the Binhai station to Banqiao station displayed in Table II, transmission power could achieve stability control limits, the line current fluctuation situation are shown in Figure I. Based on the above, it is proposed to accelerate the construction of the second single-circuit from Binhai to Banqiao station to reinforce the grid network frame. 
TABLE II. POWER FLOW VARIATIONS WHEN N-2 FAULT OCCURS

\begin{tabular}{|c|c|c|c|}
\hline Lines & $\begin{array}{c}\text { Flow } \\
\text { Before } \\
\text { (MW) }\end{array}$ & $\begin{array}{c}\text { After } \\
\text { (MW) }\end{array}$ & $\begin{array}{c}\text { Varitions } \\
\text { (MW) }\end{array}$ \\
\hline Fengnan $\sim$ Lutai & 1509 & 2177 & 668 \\
\hline Lutai $\sim$ Binhai & 1259 & 1968.6 & 709.6 \\
\hline Binhai $\sim$ Banqiao & 1318.7 & 1919.3 & 600.6 \\
\hline $\begin{array}{c}\text { Banqiao } \\
\text { SouthTianjin }\end{array}$ & 661.8 & 1547.2 & 885.4 \\
\hline
\end{tabular}

Binhai-Banqiao Active Power

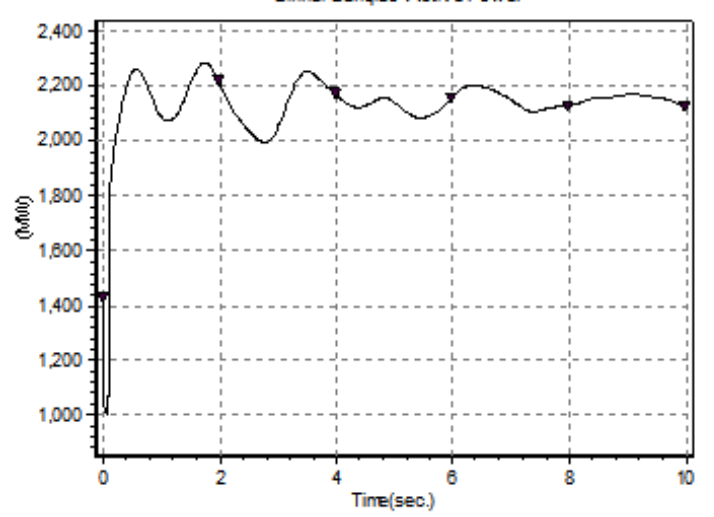

FIGURE I THE POWER VLOW VARIATIONS IN BINHAI-BANQIAO WHEN N-2 FAULT OCCURS

In summary, UHV grids transmit power flow heavily. When power shifting happened in low power grid under abnormal operation mode, it is supposed to concern about channel capacity of power flow transmission, when weak link occurred, strengthening measures should be taken to ensure power grid operation security .

\section{CONCLUSION}

After $1000 \mathrm{kV}$ AC UHV landing, power supply reliability of network receiving end has been improved and it will provide power support for regional development. At the same time, the formation of electromagnetic loop network makes significant changes in the power grid security and stability characteristics, especially upgrades the complexity of power grid operation. This paper chooses three important problems in the study of power grid security and stability, and puts forward some constructive suggestions.

1) The short-circuit current of $500 \mathrm{kV}$ substations in UHV near district increased obviously. Adjusting grid structure is still the main method to suppress short-circuit current, but the installation of current limit devibes will become an important option with the development of the technology.

2) The reactive power balance between UHV and $500 \mathrm{kV}$ power grid and voltage coordination control characteristics should be strictly verified. Reactive voltage optimization should he carried out when it is necessary, grid operators will adjust reactive power configuration timely in UHV landing near region and pay more attention about power grid voltage stability with increasing proportion of receiving grid external power supply.
3) When UHV power grid power flow transmission runs in heavy mode and flow shifting happens from $1000 \mathrm{kV}$ to $500 \mathrm{kV} /$ $220 \mathrm{kV}$ power grids network, there is a current surge in transfer channel evidently. Measures should be taken to strengthen the network frame if transmission channel is expected take overload risk.

\section{REFERENCES}

[1] Yang Dong,Liu Yutian .Influence of electromagnetic loop in early ultra-high voltage grid[J]. Electric Power Automation Equipment,2009,29(6): 77-80.

[2] Yao Yingbei,Miao Yuancheng,et al.500kV Short-Circuit Current Control Strategy in the initial Operation Stage of East China Grid UHV AC transmission Project[J].East China Electric Power,2014, 42(12): 2775-2778.

[3] Chen Lili, Huang Minxiang, Zhang Hong.et al.An optimization Strategy for Limiting Short Circuit Current [J].Automation of Electric Power Systems , 2009, 33(11):38-42.K. Elissa, "Title of paper if known," unpublished.

[4] Chen Hao,Shen Tugang,Cao lu.et al.Construction of the Second and Third Defense Lines of UHV AC Grid [J].East China Electric Power,2014, 42(12): 2770-2774.

[5] Luo Tao,Liu Lixia,Wang kui, et al.Influence of UHV Grid on Short-Circuit Current of Tianjin $500 \mathrm{kV}$ Grid and Its Restrictive Measures [J]. Electric Power Construction,2015,36(8) : 79-83.

[6] Ye Jian, Li Mingjie, Zhou Ji.et al. Research on Reactive Power and Voltage Control Strategies for the UHV AC Demonstration Project [J]. Proceedings of the CSEE,2009,29(22) : 25-29. 